\title{
Narrative collisions, sociocultural pressures and dementia: the relational basis of personhood reconsidered
}

\begin{tabular}{|r|l|}
\hline Journal: & Sociology of Health and IIlness \\
\hline Manuscript ID & SHI-00203-2015.R2 \\
\hline Sunuscript Type: & Original Article \\
\hline Subject Area: & $\begin{array}{l}\text { Dementia / Alzheimer's < RESEARCH AREAS, Gender < RESEARCH AREAS, } \\
\text { Identity < RESEARCH AREAS, Marital relationships < RESEARCH AREAS, } \\
\text { Interviewing (qualitative) < METHODS AND METHODOLOGY, Narrative } \\
\text { method < METHODS AND METHODOLOGY }\end{array}$ \\
\hline Abstract: & $\begin{array}{l}\text { The concept of personhood developed by Tom Kitwood highlights that the } \\
\text { experience of dementia has relational dimensions that transcend the } \\
\text { neurodegenerative impacts of the condition. This relational focus, however, } \\
\text { has been narrowly conceptualised, with the impact of broader sociocultural } \\
\text { factors on experience underplayed. The empirical exploration of interaction } \\
\text { also requires reinforcement: a tendency for dyadic studies to portray } \\
\text { findings in an individualised format hinders the interrogation of } \\
\text { interpersonal negotiations. This article draws upon qualitative research that } \\
\text { employed a joint interview approach, interviewing men with dementia and } \\
\text { their spousal carers together. The focus on a dyadic case study from this } \\
\text { research enables methodical exploration of the experience of living with } \\
\text { dementia. This is realised by considering the socially-framed perspective of } \\
\text { each person, and then how their perspectives are interwoven within } \\
\text { interactional exchanges. This provides a platform for the evaluation of the } \\
\text { current decontextualised notion of personhood and its implications. It is } \\
\text { concluded that a sociologically-informed perspective can help to reinforce } \\
\text { the academic understanding of personhood. }\end{array}$ \\
\hline \hline
\end{tabular}


Narrative collisions, sociocultural pressures and dementia: the relational basis of personhood reconsidered

\author{
Edward Tolhurst ${ }^{1}$, Bernhard Weicht ${ }^{2}$ and Paul Kingston ${ }^{3}$ \\ ${ }^{1}$ Faculty of Health Sciences, Staffordshire University, Stafford, UK \\ 2 Department of Sociology, University of Innsbruck, Innsbruck, Austria \\ 3 Centre for Ageing Studies, University of Chester, Chester, UK
}

\begin{abstract}
The concept of personhood developed by Tom Kitwood highlights that the experience of dementia has relational dimensions that transcend the neurodegenerative impacts of the condition. This relational focus, however, has been narrowly conceptualised, with the impact of broader sociocultural factors on experience underplayed. The empirical exploration of interaction also requires reinforcement: a tendency for dyadic studies to portray findings in an individualised format hinders the interrogation of interpersonal negotiations. This article draws upon qualitative research that employed a joint interview approach, interviewing men with dementia and their spousal carers together. The focus on a dyadic case study from this research enables methodical exploration of the experience of living with dementia. This is realised by considering the socially-framed perspective of each person, and then how their perspectives are interwoven within interactional exchanges. This provides a platform for the evaluation of the current decontextualised notion of personhood and its implications. It is concluded that a sociologicallyinformed perspective can help to reinforce the academic understanding of personhood.
\end{abstract}

Keywords: Dementia / Alzheimer's, Gender, Identity, Marital relationships, Interviewing (qualitative), Narrative method 


\section{Introduction: the conceptualisation of personhood}

Personal relationships are recognised as a key contextual influence upon the experience of dementia. An exclusive focus on dementia as a state of disease and the substantial strain it places upon people's lives can result in challenges of the condition being exacerbated and, at worst, lead to cruelty due to lack of care. As a consequence, person-centred approaches (in contrast to illness-centred) offer counterbalance by emphasising that people live their lives within interdependent relationships, which can enable people with dementia to sustain a positive personal identity.

The relational basis of experience pertains to the concept of personhood, which was pioneered by Tom Kitwood who is recognised as one of the most influential authors on the experience of dementia (Baldwin and Capstick, 2007). Kitwood defined personhood as "a standing or status that is bestowed upon one human being, by others, in the context of relationship and social being. It implies recognition, respect and trust" (1997:8). Dementia, accordingly, cannot be understood solely with reference to the neurodegenerative impacts of the condition, as human life is based on the interconnectedness and interdependencies of relationships. An individualised perspective of neurological or biological being does not, therefore, represent the essence of lived experience. The relational basis of experience endures for a person with dementia, and this means that those with the condition should not be "downgraded into the carriers of an organic brain disease" (Kitwood, 1997:7).

The maintenance of personhood therefore depends upon positive relational conditions, for example, the endorsement and support of other people. Kitwood 
(1990) however also warned that negative relational conditions can impact upon people with dementia, contributing to a 'malignant social psychology'. This refers to attitudes and behaviours adopted by (well-meaning) carers that undermine the experiential conditions of people with dementia. The nature of relationships and the care environment require an appropriate degree of scrutiny, so that such 'malignant' social factors can be identified and resisted.

While the importance of immediate relationships, prompted by Kitwood's approach to personhood, offers a significant advancement of the understanding of dementia, several authors have highlighted that there is a tendency to overlook how these relationships are framed by sociocultural factors (e.g. Innes, 2009; Bartlett and O'Connor, 2010). The grounding of Kitwood's psychological approach has been offered as one of the reasons why the experience of dementia remains scrutinised in limited terms within social science. For example, while Kitwood sought to address defective contexts of care, he drew little on concepts from sociology and consequently more extensive social influences were given little consideration (Baldwin and Capstick, 2007). Furthermore, his "unwavering commitment to the person with dementia" (Davis, 2004: 376 original emphasis) offers an individualistic rather than a genuinely relational conceptual starting point. Hence, Kitwood's approach advances understandings of dementia beyond a limited view of its biological basis, but then offers a narrow view of experience which itself requires broader contextualisation.

Higgs and Gilleard (2015) also warn that under Kitwood's approach, personhood is a status attributed to the person by others. Personhood is thus not asserted by people 
with dementia themselves, which means that their own agency in the process is lacking: it is a status bestowed, rather than something actively shaped by the person with the condition (Baldwin and Capstick, 2007). Taking personhood seriously therefore requires a comprehensive, sociological analysis of the constructions and attributions impacting upon all those involved in the maintenance of interpersonal relationships.

A sociologically-informed perspective drawing on the broad feminist literature on care and the ethics of care (Tronto, 1993; Twigg, 1997; Bowlby et al., 2010; Weicht, 2015) offers resources that can help to expand this narrow orientation, by embedding experience and interactions between partners in relationships within sociocultural structures and understandings. It has been claimed that academic endeavours have devised an effective relationship-centred approach, illuminating impacts upon wellbeing at an interpersonal level, but that this requires supplementing with attention to sociocultural elements of the social fabric (Keady and Burrow, 2015). It is something of a category mistake, however, to view the interactional order and broader social conditions as neatly separable domains of enquiry. These conditions do not comprise a discrete element of analysis to be addressed in post-hoc fashion, but are constitutive of the interactional situation: the "conditions of the situation are in the situation" (Clarke and Friese, 2007: 364 original emphasis).

In addition to this theoretical scrutiny and societal embedding, personhood also requires particular methodological reinforcement. It is not just the case that personhood is conceptually devised in narrow social terms, but that the interactional 
basis of relationships also requires greater research attention (Molyneaux et al, 2012). Social contexts cannot simply be appended to interaction in a top-down theoretical manner. Instead, a socially-framed understanding of dementia requires a cogent empirical platform at the level of experience and immediate relationships.

Even when dyadic research approaches are employed, interaction has received insufficient direct attention. Joint interviews valuably enable access to the subjective viewpoints of two respondents, but also enable insights into conversational exchanges. Nevertheless, one notable tendency is for data to be presented in an individualised format with interactions not directly conveyed. Such a pattern is evident in Robinson et al (2005), who focus exclusively on individual responses and do not present what can be termed 'interactional data'; that is, data which shows conversational interactions between participants. The interview is treated as a site where subjective viewpoints are obtained (and disaggregated from their relational context), rather than as a setting whereby interaction comprises a phenomenon for investigation in itself.

Based on the model of personhood inspired by Kitwood, this article focuses on the societal conceptualisations that shape the experience of dementia within concrete relationships. By drawing upon qualitative research that explored relationships between men with dementia and their spousal carers ${ }^{1}$, this article illuminates how a sociological perspective can help to construct and utilise an empirical platform which can fortify the understanding of personhood. A joint interview approach allows the exploration of both subjective perspectives and interactional exchanges within spousal dyads where one member of the couple has been diagnosed with dementia. 
Within this exploration the term 'narrative collisions' is advanced, which sets out to illuminate the breadth of influences and pressures that shape interpersonal negotiations.

\section{Literature context: spousal dyads and interaction}

While it is noted above that interaction has received limited empirical attention, a small number of qualitative dementia studies do set out to convey the conversational exchanges within spousal couples. A joint interview study that addresses interactional data extensively is Molyneaux et al, (2012), and this is the exclusive format of data that they present. Their article builds upon the notion of 'couplehood' (Hellström et al, 2007), which asserts how couples strive positively to maintain the balance of their relationship. The identified interactional themes in Molyneaux et al therefore focus on reciprocity and the mutual basis of experience, including how couples maintain their relationship and adopt a shared approach to the challenges posed by the condition. The orientation is thereby to the positive co-construction of a shared identity (see also Davies, 2011). It can be queried, however, whether this focus on couplehood could potentially lead to the distinctive subjective perspectives of the members of the dyad from being under-represented.

Clare and Shakespeare (2004) also present an exclusive focus on interactional data in their study of how the impact of forgetting is negotiated. Short conversations between people with dementia and their spousal carers were recorded (without an interviewer present). This process demonstrated how the conversational strategies of each partner might conflict. For example, the person with dementia sometimes adopted a 'psychological' resistance to the condition, offering a normalising account 
in the endeavor to resist being positioned negatively and as a burden. In response, carers would not always 'collude' with these accounts, presenting instead a 'political' resistance to their circumstances: this relates to the requirement to "retain a voice, and to be able to express and discuss fears and feelings openly and honestly" (Clare and Shakespeare, 2004: 226).

Studies that focus on interactional data therefore draw out different factors which shape relationships that are affected by dementia: this relates to the need to reconcile individual identities with the shared identity of the spousal relationship. The concept of couplehood, endorsed by Molyneaux et al, indicates that a shared identity is readily pursued and achieved by people with dementia and their carers. Clare and Shakespeare, on the other hand, suggest that this goal is rendered challenging by the competing subjective positions of the person with dementia and the carer.

These alternative perspectives demonstrate that there is an enduring requirement to engage in exploration of how personhood is sustained within relationships. It is crucial, however, from both a theoretical and a methodological perspective, to situate the subjective accounts and the conversational exchanges within an analysis of the socially constructed meanings of what matters to the couple. In order to identify how these meanings intersect with palpable relational negotiations this article draws upon a joint interview study, focusing on one case specifically. This approach allows the different elements that shape and configure the meaning and experience of dementia within the context of a particular relationship to be traced.

\section{Method}


The article utilises data from a dyadic case study drawn from a qualitative research project. A joint interview approach was undertaken with 14 dyads: men with dementia and their spousal carers were interviewed together in their family home. ${ }^{2}$ The gender-based orientation of this research was adopted to obtain in-depth insights into spousal relationship dynamics when the man has been diagnosed with dementia. The research set out to obtain an understanding of the experience of living with dementia, via elaborate respondent accounts on their spousal relationship, relationships with other family members, and the professional support they were accessing. Dyads were interviewed twice in the endeavour to obtain extensive experiential insights, with a six-month interval between these interviews.

The couple from which this article draws its data was selected as their interviews were among the most balanced in this research in terms of input from both respondents. The man with dementia, David ${ }^{3}$, was 64 at the time of the first interview, while the carer, Florence, was 52. David is defined as having 'early onset dementia', which refers to the onset of the condition prior to the age of 65 (Alzheimer's Society, 2015). The focus on a person with early onset dementia is also useful, as research has tended to focus on older people with the condition (Clemerson et al, 2014).

Both David and Florence are still in employment: David works in a distribution business, while Florence works in a clinical role within health/social care. They have been married for 10 years. David was diagnosed with Alzheimer's disease six months prior to their first interview in this research. Each of the joint interviews (with 
David and Florence interviewed together) lasted for approximately 90 minutes. The couple was recruited via a National Health Service (NHS) Trust's dementia service ${ }^{4}$.

In keeping with the endeavour to obtain extensive accounts from respondents, narrative analysis was undertaken of transcripts (Riessman, 2008). The aim of the analytical process was to establish the key subjective themes expressed by the man with dementia and the carer respectively, but also how these narrative themes intersect within conversation. In practical terms, the transcript was parsed on multiple occasions with respective focus on these analytical stages, to establish key narrative themes and their relational construction. The first stage required the interrogation of the subjective account presented by the man with dementia; the second stage focused on the carer's account; while the final stage evaluated interaction, i.e. how subjective perspectives were negotiated within conversational exchanges. Building upon this analytical approach, a distinctive incremental approach to the presentation of findings is conveyed: the (socially-framed) subjective perspective of each participant is addressed, and this offers a springboard to the evaluation of how these viewpoints are interwoven within interactional exchanges. This approach shows how narrative relates to the presentation of personal identity; however, it also demonstrates how stories are co-constructed by talk-in-interaction with others (Squire et al, 2008).

It has to be recognised that relationships are diverse and shaped by a breadth of factors: the specific experiences noted in the findings and the format of their expression are, of course, particular to the selected dyad. Inter alia, this couple was among the youngest in the sample, and age is a factor that will shape experience. It 
should also be recognised that David had only recently been diagnosed with dementia, and was able to communicate his views clearly and extensively. When a person is in a more advanced stage of dementia this is likely to impact upon their scope to negotiate conversational exchanges (Clare and Shakespeare, 2004). Nevertheless, the selected case does represent the principal subjective themes and conversational strategies that were identified across the 14 dyads that participated in this research. Focusing on one couple to articulate these factors offers a coherent representation of the construction and co-construction of narratives, and the challenges of reconciling a personal account with a shared account of the relationship.

\section{Subjective perspectives ${ }^{5}$}

\section{The man with dementia}

It appeared that a key aim for David in the interviews was to present a positive depiction of his experience since being diagnosed with dementia. In the following excerpt David acknowledges that he had encountered threats to his self-esteem at the onset of the condition, but he also states that the impacts of the medication following the diagnosis have ameliorated these difficulties. For example, his scores within cognitive function tests have improved, thus re-establishing his sense of competence:

I suppose once they actually, definitely diagnosed that l'd got early stages of Alzheimer's, at that point they began to input with drugs. Things like that which gave me a lot more security and made me feel a lot happier and I just felt that I wasn't as dim as I thought I was [laughs]. Because I really had a bad time before all this happened. I was really struggling and I felt embarrassed about struggling. But the girls that have come out to me, they've come out and they've put me on different tests and as I work my way through the tests l've got better and 
better at working out the tests. In fact the last test I had I think I got 34 out of 35 .

David also refers to his interactions within his workplace. His reference to other people regarding him as normal indicates the social pressures engendered by the anticipated impacts of the dementia. David, however, expresses his ability to function well in interpersonal situations, which offers a sense of continuity with his previous levels of performance:

I just feel most folks regard me at the moment as perfectly normal. The drivers will all wander in and make coffee, there's chatter and a natter. Nobody looks at me and says you are completely off your rocker or whatever.

In the following excerpt, David discusses his working role, and also his ability to engage in a manual task with skill and precision. The centrality of ongoing competence to David's sense of self is apparent in his discussion of his retained abilities. The emphasis on both the still functioning body and the positive recognition by others not only reinforce the normativity of 'vitalism' (Greco, 2009) but also the discursively created 'polarity between dependent, vulnerable, innocent, asexual children and competent, powerful, sexual, adult citizens' (Shakespeare, 2000: 15). The importance for men with dementia to retain a sense of purposeful activity is also captured by Phinney et al (2013). The assertion of sustained levels of skilful endeavour seems to relate to a sense of personal value and contribution:

I've had a busy day today. We ship an awful lot of barbeques all over the country. I spent most of my day building. You have to wrap them, put timbers under these big concrete barbeques and nail them together [...] I can hit the hammer on a nail deadon every time.

The importance of social contribution is also underscored below. David mentions that he has been offered the opportunity to attend a dementia support group; however, 
he does not yet wish to attend and if he does in the future it would be to help others rather than to seek help for himself. In fact both the opportunity to help others (being able to provide help to those needing it) and to reject help himself (the horror of needing help) appear to enhance David's sense of self and status (see also Dean and Rogers, 2004). Again, the focus of his account is on his personal improvement. The use of the word 'we' is also notable, and this indicates a shared experiential orientation within the couple:

I must admit we haven't taken it up. Because I feel very happy with how things are going. I'm not saying that in the future we wouldn't. If things get a bit - it could possibly be a good place to go to, and talk to other people in the same position. Or give advice to people in there who are perhaps newly diagnosed. I could be some help to them. To say that l've been there and l've done it and there are ways of improving yourself.

\section{The carer}

While David acknowledged the trials of the diagnostic process he converted this into a positive account of his situation. Florence, however, focused more closely on the emotional strains she encountered during this process. Below she discusses the impact of the clinician delivering the diagnosis of Alzheimer's and refers to their particular disquiet with the clinician's reference to life expectancy during this meeting:

I just wanted to gag her. I wanted to say, “I don't want this now. Come back and tell us that on another day, I don't want David to hear this." [...] when she had gone it was the first thing David said. We then just sat and sobbed.

Florence considers the changes to their circumstances and also contemplates the impacts that this will have in the future. She states her need to reconcile her caring 
role with her work commitments, which indicates the tension between balancing her own needs with providing care (Quinn et al, 2015). David is currently able to drive, but Florence anticipates the implications of the time when his driving licence might be revoked and he is subsequently no longer able to go to work:

I really hope the licence can continue. That's a big thing, because l'll be sitting at work thinking I need to go now because David will have been on his own from ten-to-seven in the morning. But I'm planning, I might have to ask if I can work at home more and stuff, but again that changes your dynamics and work with your staff.

The anticipation of care responsibilities and how they will impact on her life is not the only difficulty faced by Florence. She discusses the frustrations she encounters with David's behaviour but also expresses guilt at feeling these emotions. It has been noted that recognition of the impact of the condition upon behaviour can remove the 'legitimacy' of carers' frustrations, with such feelings replaced by guilt (Walters et al, 2010). This indicates that there is something of a recursive challenge associated with caring: negative emotions such as frustration beget other negative emotions:

I try and not feel selfish, because at times sometimes I want to kill you don't I? If you lose things and so on. And that's quite difficult because then you feel mean. Because there's a reason, there's a condition that's causing it.

A further moral trial is presented when Florence contemplates the idea of attending a support group for carers. She would not feel able to attend for personal reasons related to her work role, as she believes she would be unable to relinquish her clinical mindset within the support group setting. This perspective generates feelings of guilt: Florence appears to perceive that she is placing her own preferences ahead of the shared needs of the couple, and accordingly she feels selfish: 
I think what I would tend to do is become the clinician in that. And I would be doing the "have you thought of doing this, and have you thought of doing that?" Now maybe that is very selfish of me, but I kind of don't want to do that because I do it every day. No, maybe we'll get to that stage where we'll feel it will be helpful, but I almost feel - so maybe that's very selfish, that is very selfish. But I don't want to do it at the moment.

\section{Social influences upon subjective accounts}

The analysis of the data above shows the different perspectives of David and Florence. David offers a positive account oriented to ongoing activity, independence and enduring capabilities. Alternatively, Florence's account is more negative and oriented to her changing circumstances and associated feelings of frustration and guilt. She finds herself in the position of having to juggle competing societal expectations of remaining independent/active with being a good carer (Pickard, 2010). While the immediate interactional setting of the interview (comprising the man with dementia, the carer and the interviewer) will influence the expression of these views, the impact of wider social influences must also be acknowledged. This relates to the dialogic basis of the narrative analytical approach: this recognises how subjective 'voices' within conversation are not just directed to co-present individuals, but are also pervaded by sociocultural representations and ideals. Narrative is thereby never a singular phenomenon but is 'polyphonic', with the influence of social discourses detectable within the person's account (Sullivan, 2012).

As indicated, for the person with dementia there are a range of discourses likely to compound personal challenges. A condition such as dementia intersects with the aim to sustain a preferred identity (Charmaz, 1994), as it presents the threat that the 
person will be labelled as defective with reference to key sociocultural values. A duty and necessity to cope self-sufficiently defines the increasingly individualised basis of contemporary social conditions (Bauman, 2011). As a corollary, a strong value is placed upon the importance of personal independence and autonomy, alongside related moral imperatives of rationalism and economic contribution (Post, 2000). Dementia is accordingly positioned as the antithesis of agentic mental competence (Williams et al, 2012).

David repeatedly asserted his ability to continue his life as an independent and competent person despite his diagnosis of dementia. This could be to counter the threat that he will be judged negatively if he cannot measure up to the core societal values of independence, autonomy and individual contribution. Such cultural norms of independence/dependence relate closely to conceptualisations of personhood: "Dependency is a sign of not being healthy, of being passive, of not being self-reliant and not being a 'proper' person in society" (Weicht, 2011: 214). David's perceived role at the dementia support group, helping others but not needing help himself, underscores the potency of these social norms. This could represent the goal to resist societal constructions of dementia that could position him in a 'helpless victim role' (MacRae, 2008). Maintaining a sense of personal contribution could also reinforce David's position within the spousal relationship, thus maintaining a relationship of equals and resisting a carer/cared-for relational configuration.

The carer's personal context is also strongly shaped by cultural discourses, and these relate to the aforementioned constructions of illness. As illness is associated with an undesirable state of dependency, it requires the person who undertakes 
caring duties to be defined as a committed and selfless person who places the interests of the 'sick' before their own. While this discourse might ostensibly offer an endorsement of the value of 'caring', it risks imposing pressure upon carers to fulfil their roles with unremitting commitment. This accordingly prompts feelings of guilt if the carer feels emotions not consistent with such values, as represented by Florence's feelings when she acknowledges her frustrations with David's behaviour.

The feminist literature on care has continuously shown that care relationships cannot be understood without a focus on the societal meaning of gender constructions (Bowlby et al., 2010). Labels associated with illness related to passivity, dependence and a subordinated status (Charmaz, 1994) clash with societal notions of masculinity that are predicated on autonomy and control. "Being a patient contradicts the very definitions of manhood, leaving a person vulnerable, weakened and dependent" (Coston and Kimmel, 2013:194). Again, this is consistent with the sense that David's positive assertions of purposeful activity, social contribution and competence are offered to resist such threatening cultural norms. The influence of other characteristics, such as age, should also not be discounted. As a younger person with dementia, David is confronted with the risk of being prematurely aligned with negative discourses on old age associated with infirmity and dependency (Higgs and Rees-Jones, 2009).

Gendered meanings of care also affect the experience of carers. For example, caring is defined as a natural female role associated with nurturing, maternal values (Ungerson, 2000; Coston and Kimmel, 2013). This impinges upon female identity, defining feminine subjectivity as well as moral worthiness (Paoletti, 2002). It is also 
argued that female self-identity is acutely defined by significant relationships: women are consequently placed under particular pressure with regard to what could be termed 'relational competence'; that is, their ability to maintain positive close relationships (O'Connor, 1995). These pressures could relate to the intense moral concerns apparent in Florence's deliberations over attending a support group for carers. Cultural constructions of femininity mean that "a concern with individual survival comes to be branded as 'selfish' and to be counterpoised to the 'responsibility' of a life lived in relationships" (Gilligan, 1982:127). An ethics of care that moves beyond a 'carer/cared for' dichotomy, and which acknowledges that interdependency is the defining feature of social relationships, could help to overcome such gendered conceptualisations of caring (Weicht, 2015).

\section{Interactional data}

\section{The collision of socially-framed narratives}

The exploration of data thus far demonstrates how the alternative narrative strategies of both interviewees are positioned with reference to broader sociocultural factors that shape roles, relationships and individual narratives. The way that these subjective perspectives are interwoven within interactional exchanges is now evaluated. The following conversational exchange shows David's preference of presenting a positive view of his situation, and also Florence's tendency to present a more negative account:

David: I just feel a lot more in charge of myself, with working and doing things. I just feel much happier. I've got a goal, l've got something to do. Being at work helps me dramatically [...]

Florence: But I think for me, it gave me all the responsibility. Having that diagnosis I then felt l've got to deal with this. It will be me managing this situation. And I think for me, it was a huge impact. Absolutely huge. 
It is not just the case, however, that alternative views are held by each person, but that these perspectives interrelate and present potential problems that will require negotiation. Below, Florence again refers to the impact of being informed about life expectancy at the diagnosis. Her response collides with David's endeavour to offer a more positive account that seeks to distance him from this particular period. He concentrates on his improvement and reasserts that the medication regime offers him a sense of control over, and resistance to, the condition so that he has essentially recaptured his 'past self' (Charmaz, 1994):

Florence: It was a difficult delivery compounded by information about longevity and then we were asked to feed back on the delivery and neither of us was in a fit state to do that. But my feedback would have been that neither of us wanted to hear about life expectancy at that point. I think it was difficult enough having to think about the diagnosis without having the extra burden of that.

Interviewer: Is that how you felt as well David?

David: Well to be honest with you, when [the psychiatrist] came in and she told me that, I was somewhat shocked but almost relieved that I knew there was something there. The way that she put it to me, 'I know, yes you've hit upon it.' I mean, she told me in a very nice way, didn't she?

Florence: But in terms of the life expectancy?

David: Oh yes, the life expectancy was - I mean I feel it's up to me to try and do what I can do. And listen to what they have to tell me. To take the drugs at exactly the right times [...] because the drugs, the Aricept, has just sort of really turned me around. It's had a great deal of effect on me and improved me completely.

The different approaches within the interview, by the two participants, mean that one person's expressed outlook can potentially impede the cogency of the other's account. In the excerpt below, David is concluding a lengthy section of narrative on his role at work; however, Florence then reports that David now encounters some difficulties with him feeling lonely. David, in turn, does not accept this account and 
reasserts a more affirmative view of his circumstances, highlighting his selfsufficiency:

David: ...I do all that, get all the bits of wood back together, in case we sometimes have to slice open the plastic things and wrap the wrapper all round to make it tidy.

Florence: Sometimes you are a bit lonely aren't you? You are sent to do jobs without much support, so your days can be a bit lonely so I think that's the difference.

David: Sometimes I am actually quite happy on my own.

Florence: Okay.

David: I've got a great friend of mine who l've known for years, he's a local farmer [...] just lately we've had to clear out the barns and get them ready for reuse, and it's always me that gets the job of clearing out the barn and doing everything else and sorting it all out. But I'm quite happy with that [...] I quite enjoy my own company at times, quite honestly.

The requirement for Florence to convey the source of some of her frustrations also collides with David's objective to present himself as competent and carrying on as normal. This is reminiscent of the findings of Clare and Shakespeare (2004), noted above, where it was found that spousal carers do not always 'collude' with facesaving and normalising accounts. Florence states the difficulty of David losing things which David tries to resist with humour. Florence's elaboration on this topic draws further resistance from David, which reflects his need to position any undesirable impacts of dementia in the past. The use of 'we' by Florence in this instance perhaps indicates an endeavour to claim a shared responsibility, limiting any sense she is blaming David. Alternatively, this approach could undermine David as it reduces a sense of his capacity to take personal responsibility. However, Florence also appears to seek to diminish the impact of her statements by commenting on her own fallibility:

Florence: It's the losing things.

David: I shouldn't have a coat with so many pockets in. 
Florence: No, we all lose things. But we've lost a couple of mobile phones haven't we, and hearing aids somewhere. I think we just get on with it don't we.

David: You're going back a bit. We did used to lose quite a few things. We used to leave places and realise l'd not picked something up, whereas now l'm a little bit more -

Florence: Yes, because that's mainly on holiday isn't it. Because I actually go "have you got it, where is it?" You know, things like that. You'll frequently go out in the evening without a wallet, which is a good ploy! But I can't comment because you'd got your wallet last night, and l'd left my purse at work.

With reference to the exchanges shown above, Florence to some extent seeks catharsis from the interview process and appears to feel the need to offer a credible account, from her vantage point, of the problems that they are encountering. Her feelings in relation to her caring role are gainsaid to a degree by the overtly positive account presented by David. If the situation does not contain a substantial degree of change and hardship then Florence's frustrations might not be justifiable to herself. This could, accordingly, prompt an additional personal concern that such frustrations are not morally acceptable. The incommensurability of their respective vantage points, however, also presents difficulties to David. His expressed stoicism and appeals to enduring skills and competence were challenged within the interactional exchanges: Florence's more pessimistic account risks hindering David's attempts to sustain his preferred narrative strategy.

The influence of the dementia generates particular personal and relational challenges for the couple to negotiate. This relates to the direct neurological impact of the condition, with David pursuing a psychological resistance to the condition. It also pertains to a carer/cared-for dynamic: Florence sets out to highlight the challenges of caring she is encountering and anticipating, but also appears mindful that this could subvert David's endeavour to convey a more positive impression of 
their circumstances. Gender-related norms are also likely to link with these relational pressures. These elements combine to generate a context where narrative collisions are a potential outcome of respective endeavours to express a coherent subjective identity.

The different relational positions of the man with dementia and the female carer (with reference to the condition, one another, and wider social discourses) therefore generate interactional issues for both parties. People are narrative beings, with their self-identities narratively constituted in association with others (Baldwin 2005). Narratives are therefore inherently relational and different subjective approaches can conflict with one another. David's requirement to offer a positive account based on normalcy and continuity collides with Florence's requirement to present a more negative account based on the changes she is encountering. Additionally, both construct their own narratives in response to societal demands for independence and self-sufficiency. What has accordingly been demonstrated is a dialectical collision of narrative strategies, rather than simply the carer bestowing a negative frame of reference upon the person with dementia.

These findings show two people contending with the intense biographical disruption (Bury, 1982) prompted by dementia: both individuals struggle to maintain respective preferred identities within a disrupted interactional locale, which is shaped by multiple sociocultural pressures. If the analytical orientation were to remain on copresence (divorced from its sociocultural embeddedness) then human agency is likely to be overstated with causal powers disproportionately imputed to individuals 
(Archer, 1995). The source of the person with dementia's problems would then be identified solely at the interpersonal level.

Positive care dynamics are associated with the ability and willingness of carers to support the person with dementia (Keady and Nolan, 2003), and their capacity to put the other person's needs before their own (Shim et al, 2012). The emphasis is accordingly on the individual efforts and dispositional qualities of the carer. These are, of course, factors that need to be considered when supporting people with dementia, and it is vital to address attitudes and behaviours that are expressed in the interpersonal environment (Tanner, 2013). There are, however, implications with addressing care dynamics in a manner that understates how interactional settings are shaped by wider social influences. Ultimately, a narrow conceptualisation of relationships is compatible with a blame-oriented explanatory model (Baldwin and Capstick, 2007; Bartlett and O'Connor, 2010). While Kitwood set out to distance his critique of care environments from informal carers in his later work (1997), it can be argued that the thrust of malignant social psychology risks compounding the pressures of caring: it suggests that carers are complicit in the process of generating conditions that undermine personhood (Davis, 2004).

\section{Conclusion: seeking a balanced relational approach}

As noted in the introduction, Kitwood's influential approach to personhood has been critiqued for failing to embed personhood within a sufficiently rich and extensive social context. This article has demonstrated one means by which this limitation can be addressed by supplementing the concept of personhood with findings, informed by the sociology of care, that seek to reconcile the influences of subjective, 
interactional and wider social factors. Within this analysis, the development of the term 'narrative collisions' is of particular value. This highlights the challenges inherent to interpersonal negotiations while acknowledging the complex breadth of contextual factors that shape potentially competing narrative vantage points.

The empirical identification of interactional challenges in this article in no way suggests that an intrinsic negativity underpins relationships shaped by dementia. The overall dynamic and tone of the interviews with David and Florence indicated that this was a loving and mutually supportive relationship. This was consistent more widely across the sample of this research: relationships were supportive, but narrative collisions were still apparent. The narrative collisions that were identified within spousal dyads across this research, as represented in the case study above, reinforce the findings of Clare and Shakespeare (2004) who highlighted the different strategies people with dementia and their carers employ when resisting the impacts of the condition. This article expands upon the identification of such personal strategies, relating them to broader sociocultural influences.

David and Florence both offered a sense of unity through the use of language and often ascribed the word 'we' to their experiences, which indicates the aim to coconstruct a congruent joint narrative (see also Hydén and Nilsson, 2015). The different conversational strategies that they employ, however, shows how their distinctive subjective positions and responses to social pressures render the attainment of a unified couplehood challenging. A combined account of the relationship is difficult to sustain, as it is constructed from two different sociallyframed individual perspectives. The interactions demonstrate how 'individual' 
narratives and negotiated 'shared' narratives are shaped by the interdependencies within a care relationship (Bowlby et al, 2010). Both persons relate to a number of societal demands and constructions of meanings in relation to the meaning of dementia, the normativity of independence and the moral construction of the ideal care relationship.

The exploration of data in this article therefore underscores the truism that relationships are not amenable to binary categorisation (being either positive or negative): they are complex phenomena that must be understood with reference to a breadth of experiential, interactional and contextual factors. Nevertheless, there is a trend within academic discourse that could diminish the recognition of this relational complexity. For example, the academic promotion of personhood is aligned with resistance to excessively discouraging representations of dementia. This is reinforced by a policy and academic discourse associated with 'living well' with dementia (Department of Health, 2009; Sabat at el, 2011). This approach sets out to provide a counterbalance to the prevailing view that neurodegenerative decline and carer burden are the defining aspects of lives affected by dementia. As highlighted by La Fontaine and Oyebode (2014), there is the scope for researchers within this academic context to suppress material that does not endorse a positive portrayal of experience.

While ostensibly seeking a more integrated view of relationships by reducing the distinction between people with dementia and 'healthy others' (Sabat et al, 2011), the promotion of a more positive outlook on dementia still fails to transcend a limited standpoint. The individualistic residue of the 'personhood' concept endures and this 
means that, even when the wider social context is addressed (via the aim to counter negative societal representations of dementia), this is confronted in a unitary manner that fails to account for the interdependencies of relationships. The accounts of David and Florence capture how different narrative strategies might be adopted by people living with dementia, with carers tending to express a more pessimistic worldview than their partners. The carer's more negative perspective does not align readily with the ideal being advanced under individualised academic discourses.

A manufactured stance of positivity thus generates a zero-sum situation: the aim to bolster the position of the person with dementia requires the vantage point of the carer to be diminished. The well-intentioned attempt to elevate the status of people with dementia has thereby introduced new imbalances into academic thought. The goal to counter negative societal perceptions of dementia, however, should not lead to the difficulties of carers being invalidated. Moreover, insights into the interpersonal challenges encountered by people with dementia could also be underplayed.

A conceptual basis that asserts the person with dementia 'comes first' (Kitwood, 1997) generates a prioritisation of the individual which offers a less than optimal starting point for a genuinely balanced exploration of relationships (Davis, 2004). Even when a 'couplehood' approach has been promoted this has tended to be imbalanced, focusing on the construction of a shared identity with the aim of endorsing what is perceived to be the best interests of the individual with dementia. The views of carers are accordingly at risk of being suppressed, or held accountable for generating malignant social conditions. A credible and balanced account of the experience of dementia will be more valuable to people with the condition than a 
perspective that undermines carers, potentially rendering relational conditions even more challenging. This article has shown how the application of incremental analytical focus to (socially-framed) subjective perspectives and interaction can inform an academic understanding that neither prioritises one person's account over the other, nor conflates individual viewpoints under a shared 'us' identity.

Address for correspondence: Edward Tolhurst, Faculty of Health Sciences, Staffordshire University, Blackheath Lane, Stafford, ST18 OAD, UK. Email: e.tolhurst@staffs.ac.uk

\section{$\underline{\text { Acknowledgement }}$}

We would like to thank Mark Lovatt at Staffordshire University for his comments on earlier drafts of this article. 


\section{Bibliography}

Alzheimer's Society. (2015) 'What is young onset dementia?', available from: http://www.alzheimers.org.uk/site/scripts/documents info.php?documentID=164

Archer, M. (1995) Realist Social Theory: The Morphogenetic Approach. Cambridge: Cambridge University Press

Baldwin, C. (2005) Narrative, ethics and people with severe mental illness, Australian and New Zealand Journal of Psychiatry, 39, 11-12, 1022-1029

Baldwin, C. and Capstick, A. (eds) (2007) Tom Kitwood on Dementia: A Reader and Critical Commentary. Maidenhead: Open University Press

Bartlett, R. and O'Connor, D. (2010) Broadening the Dementia Debate: Towards Social Citizenship. Bristol: The Policy Press

Bauman, Z. (2011) Collateral Damage: Social Inequalities in a Global Age. Cambridge: Polity Press

Bowlby, S. et al. (2010) Interdependency and Care over the Lifecourse. London: Routledge

Bury, M. (1982) Chronic illness as biographical disruption, Sociology of Health \& Illness, 4, 2, 167-182

Charmaz, K. (1994) Identity Dilemmas of Chronically III Men, The Sociology Quarterly, 35, 2, 269-288

Clare, L. and Shakespeare, P. (2004) Negotiating the impact of forgetting: dimensions of resistance in task-oriented conversations between people with early-stage dementia and their partners, Dementia, 3, 2, 211-232 
Clarke, A. and Friese, C. (2007) Grounded theorizing using situational analysis. In Bryant A. and Charmaz, K. (eds) The Sage Handbook of Grounded Theory. London: Sage. pp. 363-397

Clemerson, G. et al. 2014. Towards Living Well with Young Onset Dementia: an Exploration of Coping from the Perspective of Those Diagnosed, Dementia, 13, 4, 451-466

Coston, B. and Kimmel, M. (2013) Aging men, masculinity and Alzheimer's: caretaking and caregiving in the new millennium. In Kampf, A. et al. (eds) Aging Men, Masculinities and Modern Medicine. London: Routledge. pp.191-200

Davies, J.C. (2011) Preserving the 'us identity' through marriage commitment while living with early-stage dementia, Dementia, 10, 2, 217-234

Davis, D.H. (2004) Dementia: sociological and philosophical constructions, Social Science \& Medicine, 58, 2, 369-378

Dean, H. and Rogers, R. (2004) Popular discourses of dependency, responsibility and rights, in Dean, H. (ed.) The Ethics of Welfare: Human Rights, Dependency and Responsibility. Bristol: The Policy Press. pp. 69-88

Department of Health. (2009) Living Well with Dementia: A National Dementia Strategy. London: DH Publications

Gilligan, C. (1982) In a Different Voice: Psychological Theory and Women's Development. Cambridge, MA: Harvard University Press

Greco, M. (2009) On the art of life: a vitalist reading of medical humanities, The Sociological Review, 56, 2, 25-45

Hellström, I. et al. (2007) Sustaining 'couplehood': spouses' strategies for living positively with dementia, Dementia, 6, 3, 383-409 
Higgs, P. and Gilleard, C. (2015) Rethinking Old Age: Theorising the Fourth Age. London: Palgrave

Higgs, P. and Rees-Jones, I. (2009) Medical Sociology and Old Age: Towards a Sociology of Health in Later Life. London: Routledge

Hydén, L-C. and Nilsson, E. (2015) Couples with dementia: positioning the 'we'. Dementia, 14, 6, 716-733

Innes, A. (2009) Dementia Studies: A Social Science Perspective. London: Sage

Keady, J. and Burrow, S. (2015) Quality of life for persons with dementia living in the community. In Kazer, M.W. and Murphy, K. (eds) Nursing Case Studies on Improving Health-Related Quality of Life in Older Adults. New York, NY: Springer Publishing. pp.309-318

Keady, J. and Nolan, M. (2003) The dynamics of dementia: working together, working separately, or working alone?'. In Nolan, M et al. (eds) Partnerships in Family Care: Understanding the Caregiving Career. Maidenhead: Open University Press. pp. 15-32

Kitwood, T. (1990) The dialectics of dementia: with particular reference to Alzheimer's Disease, Ageing \& Society, 10, 2, 177-196

Kitwood, T. (1997) Dementia Reconsidered: The Person Comes First. Buckingham: Open University Press

La Fontaine, J. and Oyebode, J. (2014) Family relationships and dementia: a synthesis of qualitative research including the person with dementia, Ageing \& Society, 34, 7, 1243-1272

MacRae, H. (2008) Making the best you can of it: living with early-stage Alzheimer's disease, Sociology of Health \& IIIness, 30, 3, 396-412 
Molyneaux, V. et al. (2012) The co-construction of couplehood in dementia, Dementia, 11, 4, 483-502

O'Connor, D. (1995) Caring for a memory-impaired spouse, Journal of Women and Aging, 7, 3, 25-42

Paoletti, I. (2002) Caring for older people: a gendered practice, Discourse \& Society, $13,6,805-817$

Phinney, A. et al. (2013) Shifting patterns of everyday activity in early dementia: experiences of men and their families, Journal of Family Nursing, 19, 3, 348-374

Pickard, S. (2010) The 'good carer': moral practices in late modernity, Sociology, $44,3,471-87$

Post, S. (2000) The Moral Challenge of Alzheimer Disease: Ethical Issues from Diagnosis to Dying, $2^{\text {nd }}$ ed. Baltimore, MD: John Hopkins University Press

Quinn, C. et al. (2015) Balancing needs: the role of motivations, meanings and dynamics in the experience of informal caregivers of people with dementia, Dementia, 14, 2, 220-237

Riessman, C. K. (2008) Narrative Methods for the Human Sciences. London: Sage

Robinson, L. et al. (2005) Making sense of dementia and adjusting to loss: psychological reactions to a diagnosis of dementia in couples, Aging \& Mental Health, 9, 4, 337-347

Sabat, S. et al. (2011) The 'demented other' or simply 'a person'? extending the philosophical discourse of Naue and Kroll through the situated self, Nursing Philosophy, 12, 4, 282-292

Shakespeare, T. (2000) Help. Birmingham: Venture Press 
Shim, B. et al. (2012) A comparative qualitative analysis of stories of spousal caregivers of people with dementia: negative, ambivalent and positive experiences, International Journal of Nursing Studies, 49, 2, 220-229

Squire, C. et al. (2008) Introduction: what is narrative research?'. In Andrews, M. et al. (eds) Doing Narrative Research, $2^{\text {nd }}$ ed. London: Sage. pp. 1-26

Sullivan, P. (2012) Qualitative Data Analysis: Using a Dialogical Approach. London: Sage

Tanner, D. (2013) Identity, selfhood and dementia: messages for social work, European Journal of Social Work, 16, 2, 155-170

Tronto, J. (1993) Moral Boundaries: A Political Argument for an Ethic of Care. London: Routledge

Twigg, J. (1997) Deconstructing the 'social bath': help with bathing at home for older and disabled people, Journal of Social Policy, 26, 211-232

Ungerson, C. (2000) Thinking about the production and consumption of long-term care in Britain: does gender still matter? Journal of Social Policy, 29, 4, 623-643

Walters, A.H. et al. (2010) The dynamics of continuity and discontinuity for women caring for a spouse with dementia, Dementia, 9, 2, 169-189

Weicht, B. (2011) Embracing dependency: rethinking (in)dependence in the discourse of care. The Sociological Review, 58(2): 205-224

Weicht, B. (2015) The Meaning of Care: The Social Construction of Care for Elderly People. Basingstoke: Palgrave Macmillan

Williams, S.J. et al. (2012) Neuroculture, active ageing and the 'older brain': problems, promises and prospects, Sociology of Health \& IIIness, 34, 1, 64-78 
Notes

${ }^{1}$ While the term 'carer' is used in this article, it is acknowledged that this term should be used with caution, as it implies the relationship is defined by a carer/cared-for dynamic (Bartlett and O'Connor, 2010).

${ }^{2}$ A further two carers were interviewed on a one-to-one basis, as their partners did not have the capacity to take part.

${ }^{3}$ The names of the interviewees have been changed.

${ }^{4}$ Ethical clearance for this research was granted by an NHS Research Ethics Committee.

${ }^{5}$ An ellipsis in square brackets highlights that some text has been removed from an interview excerpt. This is to aid the presentation of the findings and does not alter the basis of expressed perspectives, or interactions. 